\title{
Emotional Intelligence Scale: Assessing its Psychometric Characteristics in Bangladeshi Culture
}

\author{
Muhammad Akram Uzzaman ${ }^{1}$, Dr. A. K. M. Rezaul Karim²
}

\section{ABSTRACT}

After the publication of Goleman's (1995) best-selling book 'Emotional Intelligence' the term drew attention scholars (Algera, 2011) in terms of ensuring social and universal unity and for study.

Due to development of technology, increasing social unrest and competition social relationships have been declining and individualism has been arising in parallel with the rapid emotional understanding and control has arisen in order to each individual accepts and works in cooperation with an individual from another culture. But there is no valid scientific tool for measuring this important emotional intelligence behavior in Bangladesh culture. So, considering the significance of the tool, the purpose of the present study was to translate the instrument into Bangla and validate in Bangladeshi culture. A grand total of 1000 participants (491 males and 509 females) participated in the study. Exploratory Factor Analysis (EFA) which was administered on sample $1(n=500)$ identified a seven-factor of the Emotional Intelligence Scale (EIS) with 33 items. The seven factors explained $56.60 \%$ of the total variance. When analyzed the data for sample $2(n=500)$ in Confirmatory Factor Analysis (CFA), it revealed that the seven-factor model with 33 items is an acceptable fit $[\chi 2(469)=1325.99$, RMSEA $=.06$, RMR $=.08$, CFI $=.87$, GFI $=.86]$ model to the data. Moreover, the EIS showed good internal consistency (Cronbach's $\alpha=.93$ for the 1 st sample, .92 for the 2 nd, and combined sample), strong convergent, and discriminant validity. Thus, the Bangla version EIS appears to be valid and reliable and may be used in further research on emotional intelligence behavior in the country.

Keywords: Emotional Intelligence, Scale, Factor Analysis, Exploratory, Confirmatory, Validation In Bangla

\footnotetext{
${ }^{1}$ Assist. Professor, Dept. of Psychology, Jagannath University, Dhaka, India

${ }^{2}$ Professor, Dept. of Psychology, University of Dhaka, Dhaka, India

*Responding Author
}

Received: December 30, 2016; Revision Received: January 20, 2017; Accepted: January 30, 2017

(C) 2017 Uzzaman A, Karim A; licensee IJIP. This is an Open Access Research distributed under the terms of the Creative Commons Attribution License (www.creativecommons.org/licenses/by/2.0), which permits unrestricted use, distribution, and reproduction in any Medium, provided the original work is properly cited. 
Emotional Intelligence Scale: Assessing its Psychometric Characteristics in Bangladeshi Culture

Emotion has become an inevitable subject both for psychologists, philosophers, developmental researchers etc. which play an important role in social communication, personality functions, and even in cognitive processes. It is a behavioral regulator that can change from a deep feeling to a tense feeling in response to a certain situation. Experts (such as Erkus, 1994) reported that emotions get socially structured through an assembly of cultural sections. The emotional self regulation strategies that the individuals use while adapting themselves to their emotions and the concept closely related to the intellectual control is called 'emotional intelligence. Emotional intelligence can be defined as the perceiving emotions in order to support for emotional and mental development (Mayer and Salovey, 1997) which keeps successful in life and healthy in general of an individual (Bar-On, 2006).

Goleman's theory (1995) suggests that emotional intelligence includes knowing and managing of personal emotions, sympathizing with others, and manipulation of communications in order to be satisfied with them. It covers abilities like recognizing, understanding, and regulating emotions which are important for children to establish positive relationships with people (Goleman, 2001). Huffman (2008) focused that one person with high emotional intelligence combines 3 components of emotions successfully such as cognitive, physiological, and behavioral. Bhatia (2012) reported that emotional intelligence helps in understanding the emotional information and in reasoning emotions. If taken a deep thought, nothing new about emotional intelligence will be found. Family and school environment is a primary agent of child emotional development which affects the development of the child in many ways like ego concept of the child and his/her emotional and social development. From the both environment child feels, observes, and learns the emotional relationships (Warhol, 1998). Children try to understand the emotions through the attachment and modeling with parents, teachers, peers etc. (Suess, Grossmann, \& Sroufe, 1992).

Experts reported that family relationship (Nixon \& Watson, 1999), parental attachment (Rice, Cunningham, \& Young, 1997) rigorously affect emotional intelligence of a person. Even success (Goleman, 1995), achievement (Abisamra, 2000) are closely related with emotional intelligence. Without these factors, several others factors such as child's character, neurophysiology, and cognitive enhancement (Eisenberg \& Morris, 2002; Goldsmith \& Davidson, 2004); family, school, circle of friends (Parke, 1994; Walden \& Smith, 1997) etc. are the important factors for adolescents' emotional intelligence.

In several studies it was seen that successful management, social competence, and good leadership are depends on sound emotional intelligence of a person (Goleman, 2006; Barling, Slater, \& Kelloway, 2000). In recent times therefore, scientists are beginning to uncover the relationship of emotional intelligence to other phenomenon such as social bond, and their interactions in an online learning environment (Han \& Johnson, 2012), policing (Aremu, 2005), group performance (Williams \& Sternberg, 1988) etc. From the above literature it has been 


\section{Emotional Intelligence Scale: Assessing its Psychometric Characteristics in Bangladeshi Culture}

observed that the importance of studying emotional intelligence is so inevitable for psychologists, sociologists, developmental psychologists etc.

Adolescent is a crucial period for developing emotional intelligence behavior. But the matter has received little attention for the public, psychologist, and researchers in the past. Goleman's (1995) first drew attention on the importance of emotional intelligence to researchers. Though in late, the consciousness of emotional intelligence behavior during adolescence is increasing in Bangladesh. But the measurement tool of emotional intelligence of adolescent is very much scarce in Bangladeshi culture. Hyde, Pethe, and Dhar (2002), developed such a tool called Emotional Intelligence Scale (EIS) for measuring emotional intelligence behavior which covers self-awareness, empathy, self-motivation, emotional stability, managing relations, integrity, selfdevelopment, value orientation etc. But the scale has developed mainly for English language speaker. All these matters lead the present researcher to adapt and validate the EIS in Bangladeshi culture.

But for using any scale in another culture requires a validation study to be usable. Not only that inspecting factor structure or dimensionality of an instrument in a new culture is important for accurate specifications of theories (Smith \& McCarthy, 1995) and theory-driven research. The adapted EIS and results can help identify nature of the emotional intelligence behavior of adolescents and guidelines for how to minimize and develop sound emotional intelligence behavior in Bangladeshi culture.

\section{METHOD}

\section{Participants}

A total of 1064 eleventh grade adolescent students (524 males and 540 females, session: 20122013) of Dhaka Metropolitan City (DMC) were participated in this study. Participants' age ranged from 14 to 19 years with a mean of 16.43 and standard deviation of .89. Among the participants $49.25 \%$ were boys and $50.75 \%$ were girls. $23.12 \%$ of the participants were from lower class, $62.69 \%$ from middle class, and $14.19 \%$ were from upper class.

\section{Measure}

\section{Emotional Intelligence Scale (EIS)}

Developed by Hyde, Pethe, and Dhar (2002), the EIS contains 34 statements, each to be rated on a five-point scale ranging from 'strongly agree' (5) to 'strongly disagree' (1). The statements relate different components of emotional intelligence like self-awareness (4 items), empathy (5 items), self-motivation (6 items), emotional stability (4 items), managing relations (4 items), integrity (3 items), self-development (2 items), value orientation (2 items), commitment (2 items), and altruistic behavior (2 items). The obtainable score ranges from 34 to 170 where higher score indicates higher level of emotional intelligence. There are no negative items. Individual subscales scores are obtained by summing the scores belonging to a particular 


\section{Emotional Intelligence Scale: Assessing its Psychometric Characteristics in Bangladeshi Culture}

subscales. The original scale has high content validity. The split-half reliability of the scale is .88 .

\section{Future Aspiration Scale (FAS)}

The FAS was developed by Center for Urban Affairs and Policy Research (1995). It measures future and career orientation and aspirations. It consists of 6 Likert type items with 4 response alternatives such as 'very important' (4), 'important' (3), 'somewhat important' (2), and 'not at all important' (1). Point values are summed for each respondent, then, divided by the total number of responses. Higher mean scores (Ranging from 1 to 4 ) indicate stronger aspirations in a variety of education, career, and social domains. Lower mean scores indicate lower and less diverse future aspirations. The internal consistency of the scale is .60. The scale was reported to be valid (Center for Urban Affairs and Policy Research, 1995).

\section{School Engagement Scale (SES)}

The SES was developed by Fredricks, Blumenfeld, Friedel, and Paris (1983) for measuring school engagement of elementary and middle school children. The scale consists of nineteen (19) Likert type items with five response alternatives such as 'all of the time' (5), 'most of the time' (4), 'some of the time’ (3), 'on occasion’ (2), 'never’ (1) compartmentalized into three parts, such as, emotional engagement, behavioral engagement, and cognitive engagement. The obtainable score ranges from 19 to 95 where higher score indicates higher level of engagement. Among 19 items 3 items (Item no. 2, 5, 7) are negative and their scoring is therefore reversed. Individual subscale scores are obtained by summing the scores belonging to a particular subscale (Score ranges from 5 to 25 for behavioral engagement, from 6 to 30 for emotional engagement, and from 8 to 40 for cognitive engagement) while total scores were obtained by summing the scores for all the items of the scale.

The SES has good face validity, adequate internal consistency, and adequate predictive validity. Cronbach's $\alpha$ was chosen as the measure of internal consistency which suggests that the items hang well together as a construct. The Cronbach's $\alpha$ values was .77 for behavioral engagement, .86 for emotional engagement, and .82 for cognitive engagement.

\section{Children Hopelessness Scale (CHS)}

The CHS was developed by Kazdin, French, Unis, Esveldt-Dawson, and Sherick (1983). This scale measures a child's negative (Hopeless) expections for the future. It is a self-report inventory consisting of 17 items with 2 response alternatives such as 'Yes' and 'No'. 'No' responses indicate hopelessness while 'Yes' response indicate lack of hopelessness. Eight positively worded items (Items no. 1, 3, 4, 5, 6, 7, 11, and 16 are reversed coded). Responses are added to derive an overall score. A score of 17 indicates high hopelessness and a score of 0 indicates low hopelessness. The CHS has demonstrated good reliability and validity (Kazdin et al., 1983; Kazdin, Rogers, \& Colbus, 1986; Spirito, Williams, Stark, \& Hart, 1988) in children and adolescents up to age 17. The internal consistency values of the scale are .62 (Kazdin et al., 1983) and .78 (Wagner, Smith, Ferguson, Horton, \& Wilson, 2009), and one year stability is .48 (Kazdin et al., 1983). The item-total correlations of CHS range from .41 to .70 (Kazdin et al., 1983). 


\section{Hostility Scale (HS)}

The HS was developed by Derogatis, Rickels, and Rock (1976). It measures symptoms of underlying hostility, reflecting qualities such as aggression, irritability, rage, and resentment. The scale consists of 6 Likert type items with 4 response alternatives such as 'never' (1), 'once in a while' (2), 'fairly often' (3), and 'most of the time' (4). Point values are summed for each respondent and divided by the number of items. The intended range of scores is $1-4$, with a higher score indicating more hostility. The internal consistency of the scale is .73. The scale was reported to be valid (Derogatis et al., 1976).

\section{Procedure}

1 Translating the scales into Bangla. At first, written permission was taken from the author of the respective scale for translating and using it in Bangladeshi culture. Then, the English version EIS was translated into Bangla by using Team Translation (TT) technique in the present study.Translation of scale was completed following the TRAPD (Translation, Review, Adjudication, Pretesting, and Documentation) model of TT which has the following stages.

Stage 1: Translation. The researcher translated the FAS and then, sits together with the supervisor to check and modify the translations.

Stage 2: Review. Six reviewers (Two experts in English, two experts in Bangla, and two experts in Psychology) independently reviewed the translations of the scales with the translator (Researcher) and corrected the translations of some of the items (Where needed). All experts had good command both in English and Bangla. Each expert task was to inspect sentence making, wording, clarity, cultural fitness, double barrel etc. Their task was also to judge the accuracy of translation or language and the relevance/suitability of each item for measuring future aspiration in the socio-cultural context of Bangladesh. Each expert independently rated the translation using 2-point scale ( $0=$ Not correct, $1=$ Correct) and the relevancy of each item using another 2-point scale $(0=$ Not relevant, $1=$ Relevant $)$.

\begin{tabular}{|c|c|}
\hline Translation & Pretesting \\
\hline $\begin{array}{l}\text { Review } \\
\text { Adjudication }\end{array}$ & Documentation \\
\hline
\end{tabular}

Figure1.The TRAPD team translation model (Source: Harkness, 2008).

Stage 3: Adjudication. Two adjudicators (The researcher and his supervisor) decided whether the translation is ready to move to detailed pretesting. Following the reviewer's evaluation in stage 2, accuracy of translation was examined by calculating for each item the Accuracy Index $(\mathrm{AI}=$ Number of rating at 1 /Number of experts). The item yielding an AI of $1(\mathrm{AI}=6 / 6)$ was considered to be correctly and reliably translated (Karim \& Nigar, 2014). The adjudicators refined or modified 15 EIS items as these items had AI values $<1$. The experts in stage 2 
suggested some corrections to the clarity, wording, and organization of these items. The adjudicators ensured the accuracy of translation by reviewing those items $(\mathrm{AI}<1)$ in the light of their comments and suggestions. They also examined the relevance/suitability of the items in Bangladeshi culture by calculating for each item the Relevance Index (RI = Number of rating at 1/Number of experts). They considered an item yielding an RI of 1 or $.83(\mathrm{RI}=6 / 6$ or $\mathrm{RI}=5 / 6)$ to be relevant or suitable (Karim \& Nigar, 2014). All the six experts rated the relevance of each item at 1 . Thus, the second draft of the Bangla version EIS was finalized for piloting/pretesting on a small representative group of participants.

Stage 4: Pretesting/pilot study. Pilot study is important when questionnaire is translated and/or new questions are added to an existing questionnaire because an unverified questionnaire can mislead respondents during data collection and can create ambiguous or erroneous explanation during analysis (Hunt, Sparkman., \& Wilcox, 1982; Braun, 2003; Bolton \& Bronkhorst, 1996; U.S. Census Bureau, 2005). With this view pilot study was carried out on eleventh grade students of 'Uttara United School and College' $(N=100)$. It was conducted in order to test the appropriateness of the test materials, test procedures, and how the directions of administration as well as the items of the test could be acceptable and understandable to them. Participants were requested to provide information by taking comments about the readability, feasibility, clarity, comprehensiveness, easily answerable, and 'style and formatting' of the scale's items. The results are presented in the following Table 1.

Table 1, Percentages of the participants who commented on different aspects of the measure

\begin{tabular}{|l|c|c|l|c|c|}
\hline & EIS & & Yes (\%) & No (\%) \\
\hline & Yes (\%) & No (\%) & & 97 & 3 \\
\hline Readable & 90 & 10 & Comprehensive & 82 & 18 \\
\hline Logical & 87 & 13 & Easily answerable & 87 & 13 \\
\hline Clear & 89 & 11 & Style and formatting & 87 \\
\hline
\end{tabular}

From the above Table it is seen that the percentages of participants responded 'Yes' on the readability, logicality, clarity, comprehensiveness, easily answerable, and 'style and formatting' ranged from $82 \%$ to $97 \%$ for EIS which ensured good face validity of the measure. However, participants were also asked to report verbally regarding difficulty of items, typos, grammatical errors, whether easiness of instruction, questionnaire design or anything else they can spot as they go through the scales. Participants' response style, their motivation, attention during filling up questionnaires were observed and monitored. Moreover, participants' emotional reactions such as frustration, comfort level, hesitancies, facial expression were also observed. Any fruitful suggestions from participants were welcomed and recorded. Some of the items of the scale were refined according to feedback of the participants. The adjudicators carried out some necessary modifications regarding wording, abstract level, unclear perspective, response style etc. However, no item was reported to be seriously erroneous or ambiguous to be discarded. Thus, the third draft was prepared for final fielding. 
Emotional Intelligence Scale: Assessing its Psychometric Characteristics in Bangladeshi Culture

\section{Data acquisition}

In Bangladesh there is no local research ethics review committee. However, steps were taken to ensure the ethics of psychosocial research. Standard data collection procedures were followed in the study. The researcher personally met each head of the selected 'schools and colleges', narrated the general purpose of the study, discussed ethical issues, and finally got permission to collect relevant data from their students. All participants were eleventh grade college students of the selected institutions. On the appointed date and time, the researcher went to a particular 'school and college', and then to the selected class where he was introduced by the head of the institution. At the beginning, participants were briefed about the general purpose of the study and good rapport was established with them. They were informed both verbally and in writing that the investigation is purely academic and their responses to the questionnaires would be kept confidential.

Thus, after taking their consent the paper-based survey ( $3^{\text {rd }}$ draft) was administered to the participants. The survey components included an informed consent statement, sociodemographic section, and the EIS. After completion of their task, the questionnaires were collected, and they were given thanks for their sincere cooperation. In this way, the surveys were administered and data were collected over a 3-months (From June to August, 2013) period from all the participants. And 64 participants were excluded from final analyses as they provided incomplete responses to the questionnaires. Thus, the complete response rate was $93.98 \%$.

\section{Data analyses}

Each participant's responses were scored according to the scoring principles of the EIS. After getting data from 1000 participants (Those who provided complete response) in this way they were fed into computer for analyzing. The data analysis was done in three phase. At first, item analysis was done followed by Exploratory Factor Analyses (EFA) and Confirmatory Factor Analyses (CFA). The participants were divided into two groups: Odd numbered participants (sample 1) and even numbered participants (sample 2). Data for the 500 odd numbered participants were subjected to EFA whereas data for the 500 even numbered participants were subjected to CFA. However, before doing these analyses it was checked whether the data were suitable for factor analysis or not. However before carrying out factor analysis it was examined the internal consistency by investigating inter-item correlations and item-total correlations. Then, the first set of data were analyzed in EFA and the second set of data was analyzed in CFA in order to comparison to confirm the factors extracted in EFA.

\section{Factor structure of EIS}

Item analysis. The item analysis was carried out for the 34 items of the EIS (No item was eliminated in the adjudication stage of translation). The correlation matrix (Data not shown) contained no negative values and out of 561 inter-item correlation coefficients 555 (98.93\%) were significant, the average inter-item coefficients being .28. All the item-total correlations 
were significant and ranged from .33 to .84 with a mean of .58. Thus, all the items were retained in this stage.

Exploratory factor analysis. In order to examine whether data were suitable for factor analysis measures of sampling adequacy were carried out on the 34-item EIS. Inspection of the $R$-matrix revealed a good number of coefficient .30 and above (39.92\%). The KMO measure of sampling adequacy for these set of variables was .92 which falls in the range of being superb (.92 > .90; Kaiser, 1970). Bartlett's test of sphericity indicated a $\chi^{2}$ value of $7274.93(p<.001)$. All this together supports the factorability of the $R$-matrix. Data for the full set of EIS were therefore subjected to EFA. Method of PC with varimax rotation was used. The initial analysis with Eigen value $>1.00$ (the Kaiser-Guttman criterion) extracted 7-factor solution accounting for $56.61 \%$ of the total variance (Data not shown). However, an inspection of scree plot indicates a clear break after the $7^{\text {th }}$ component (Figure 2a), leading us to retain 7 components.
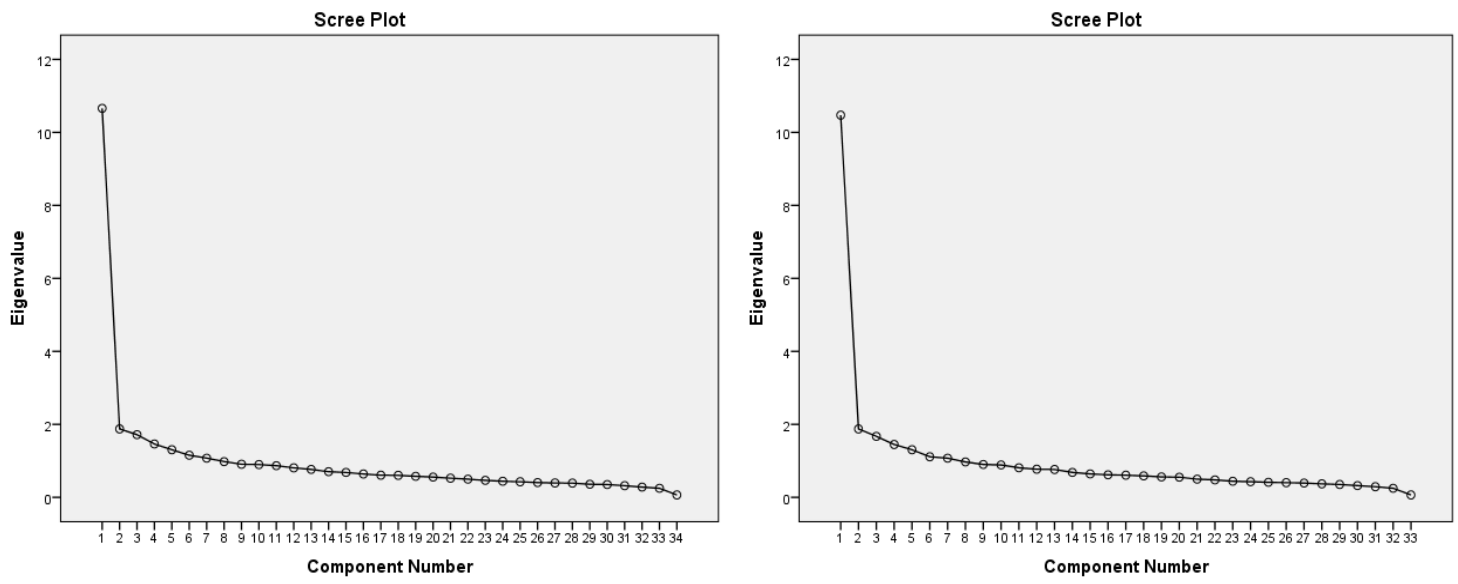

(b)

Figure 2. The scree plots generated in EFA: (a) for 34 items, and (b) for 33 items.

Considering Cattle's view, data were subjected to another EFA, limiting the number of factors to 7 with all factor loadings $<.40$ suppressed. These seven factors which were rotated to position of maximum orthogonality in 10 iterations explained together $56.60 \%$ (Table 2) of the total variance of measured variable (Data not shown), but item no. 28 loaded at $<.40$. The low factor loading indicates that perhaps item 28 cannot measure emotional intelligence in Bangladesh culture. After discarding this item data were further subjected to EFA with all factor loadings < .40 suppressed limiting the number of factors to 7. Again, a seven-factor solution (Figure 2b) of the EIS were identified which was deemed to be the most statistically and conceptually appropriate and more interpretable to the EIS. 
Emotional Intelligence Scale: Assessing its Psychometric Characteristics in Bangladeshi Culture

Table 2, Rotated factor matrix for a reduced set of EIS items (Item no. 28 discarded)

\begin{tabular}{|c|c|c|c|c|c|c|c|}
\hline \multirow{2}{*}{$\begin{array}{l}\text { Item } \\
\text { number }\end{array}$} & \multicolumn{7}{|c|}{ Factor loadings } \\
\hline & F1 & F2 & F3 & F4 & F5 & F6 & F7 \\
\hline Item 02 & .60 & & & & & & \\
\hline Item 03 & .67 & & & & & & \\
\hline Item 11 & .58 & & & & & & \\
\hline Item 12 & .65 & & & & & & \\
\hline Item 23 & & .44 & & & & & \\
\hline Item 24 & & .53 & & & & & \\
\hline Item 25 & & .59 & & & & & \\
\hline Item 26 & & .89 & & & & & \\
\hline Item 27 & & .87 & & & & & \\
\hline Item 04 & $(.43)$ & & .61 & & & & \\
\hline Item 05 & & & .73 & & & & \\
\hline Item 06 & & & .74 & & & & \\
\hline Item 07 & & & .71 & & & & \\
\hline Item 14 & & & & .64 & & & \\
\hline Item 15 & & & & .60 & & & \\
\hline Item 16 & & & & .63 & & & \\
\hline Item 17 & & & & .53 & & & \\
\hline Item 21 & & & & .60 & & & \\
\hline Item 22 & & & & .49 & & & \\
\hline Item 08 & & & & & .64 & & \\
\hline Item 09 & & & & & .73 & & \\
\hline Item 10 & & & & & .43 & & \\
\hline Item 13 & & & & & .48 & & \\
\hline Item 01 & & & & & .44 & & $(-.42)$ \\
\hline Item 29 & $(.45)$ & & & & & .41 & \\
\hline Item 30 & & & & & & .70 & \\
\hline Item 31 & & & & & & .48 & \\
\hline Item 32 & $(.48)$ & & & & & .42 & \\
\hline Item 33 & & & & & & .65 & \\
\hline Item 34 & & & & & & .58 & \\
\hline Item 18 & & & & & & & .63 \\
\hline Item 19 & & & & & & & .52 \\
\hline Item 20 & & & & & & & .44 \\
\hline $\begin{array}{l}\text { Eigen } \\
\text { value }\end{array}$ & 3.22 & 3.19 & 2.96 & 2.94 & 2.45 & 2.37 & 1.83 \\
\hline $\begin{array}{l}\text { Variance } \\
\text { explained } \\
(\%)\end{array}$ & 9.78 & 9.66 & 8.98 & 8.92 & 7.41 & 7.20 & 5.54 \\
\hline
\end{tabular}

Note. $n=500$.

Factor loadings $<.40$ were suppressed.

Items corresponding to the parenthesized loadings did not conceptually fit with the corresponding factors.

Extraction method: varimax with Kaiser normalization.

Rotation converged in 10 iterations.

(C) The International Journal of Indian Psychology, ISSN 2348-5396 (e)| ISSN: 2349-3429 (p) | 95 


\section{Emotional Intelligence Scale: Assessing its Psychometric Characteristics in Bangladeshi Culture}

Factor 1 accounts for $9.78 \%$ of the variance, Factor 2 accounts for $9.66 \%$ of the variance, Factor 3 accounts for $8.98 \%$ of the variance, Factor 4 accounts for $8.92 \%$ of the variance, Factor 5 accounts for $7.41 \%$ of the variance, Factor 6 accounts for $7.20 \%$ of the variance, and Factor 7 accounts for $5.54 \%$ of the variance. Before labeling the factors we identified four pairs of crossloadings between the factors. Specifically, item 29 was cross loaded on Factor 1 and Factor 6 with the loadings of .45 and .41 respectively; item 32 was cross loaded on Factor 1 and Factor 6 with the loadings of .48 and .42 respectively; item 1 was cross loaded on Factor 5 and Factor 7 with the loadings of .44 and -.42 respectively; and item 4 was cross loaded on Factor 1 and Factor 3 with the loadings of .43 and .61 respectively. We grouped both item 29 and item 32 under Factor 6, the factor of their smaller loadings but best conceptual fit; item 1 under Factor 5, the factor of its greater loadings and best conceptual fit, and item 4 under Factor 3, the factor of its greater loading and best conceptual fit.

Factor 1 comprises item no. 2, 3, 11, and 12 which we termed as 'Self-confidence and Analytic'; Factor 2 comprises item no. 23, 24, 25, 26, and 27 which we termed as 'Self-awareness and Development'; Factor 3 comprises item no. 4, 5, 6, 7 which we termed as 'Empathy'; Factor 4 comprises item no. 14, 15, 16, 17, 21, and 22 which we termed as 'Emotional Stability'; Factor 5 comprises item no. 1, 8, 9, 10, and 13 which we termed as 'Enthusiasm and Firmness'; Factor 6 comprises item no. 29, 30, 31, 32, 33, and 34 which we termed as 'Integrity and Commitment'; and finally Factor 7 comprises item no. 18, 19, and 20 which we termed as 'Survival'.

Confirmatory factor analysis of EIS. The CFA in the present study revealed that the sevenfactor model identified for the EIS in EFA is a good fit to the data. The obtained fit statistics are depicted in Table 4.

Table 4, Model fit indices for 33-item EIS obtained in CFA

\begin{tabular}{|l|l|l|l|l|l|l|c|}
\hline & $\boldsymbol{\chi 2}$ & df & $\boldsymbol{\chi 2}$ /df & RMSEA & RMR & CFI & GFI \\
\hline Modified fit indices & $1512.7 *$ & 474 & 3.19 & .07 & .09 & .84 & .84 \\
\hline Unmodified fit indices & $1325.99 *$ & 469 & 2.83 & .06 & .08 & .87 & .86 \\
\hline
\end{tabular}

$n=500 . * p<.05$.

The above table indicates that the value of $\chi^{2}$ was significant $(p<.05)$. The normalized $\chi^{2}$ value is $2.83(<5)$. The values of RMSEA and RMR fit well the reference values. However, the values of CFI and GFI (Unmodified) lie below the criterion values. So, MIs were examined which identified similar theoretical content between some of the items. Parameters with high MIs > 21 have been noted as potential areas for structure misfit leading to poor fit the model. Five modification index values greater than 21 were identified which indicated five correlated measurement errors, one between items 2 and 3, one between items 8 and 9, one between item 14 and 15, one between item 23 and 24 and a fifth one between item 23 and 25. So, when CFA was run allowing these items in each pair to covary the model was quite improved. The modified fit 
Emotional Intelligence Scale: Assessing its Psychometric Characteristics in Bangladeshi Culture

indices indicated an acceptable model fit to the data $\left[\chi^{2}(469)=1325.99\right.$, RMSEA $=.06, \mathrm{RMR}=$ $.08, \mathrm{CFI}=.87, \mathrm{GFI}=.86]$. The factor structure of the seven-factor solution is given in Figure 3 .

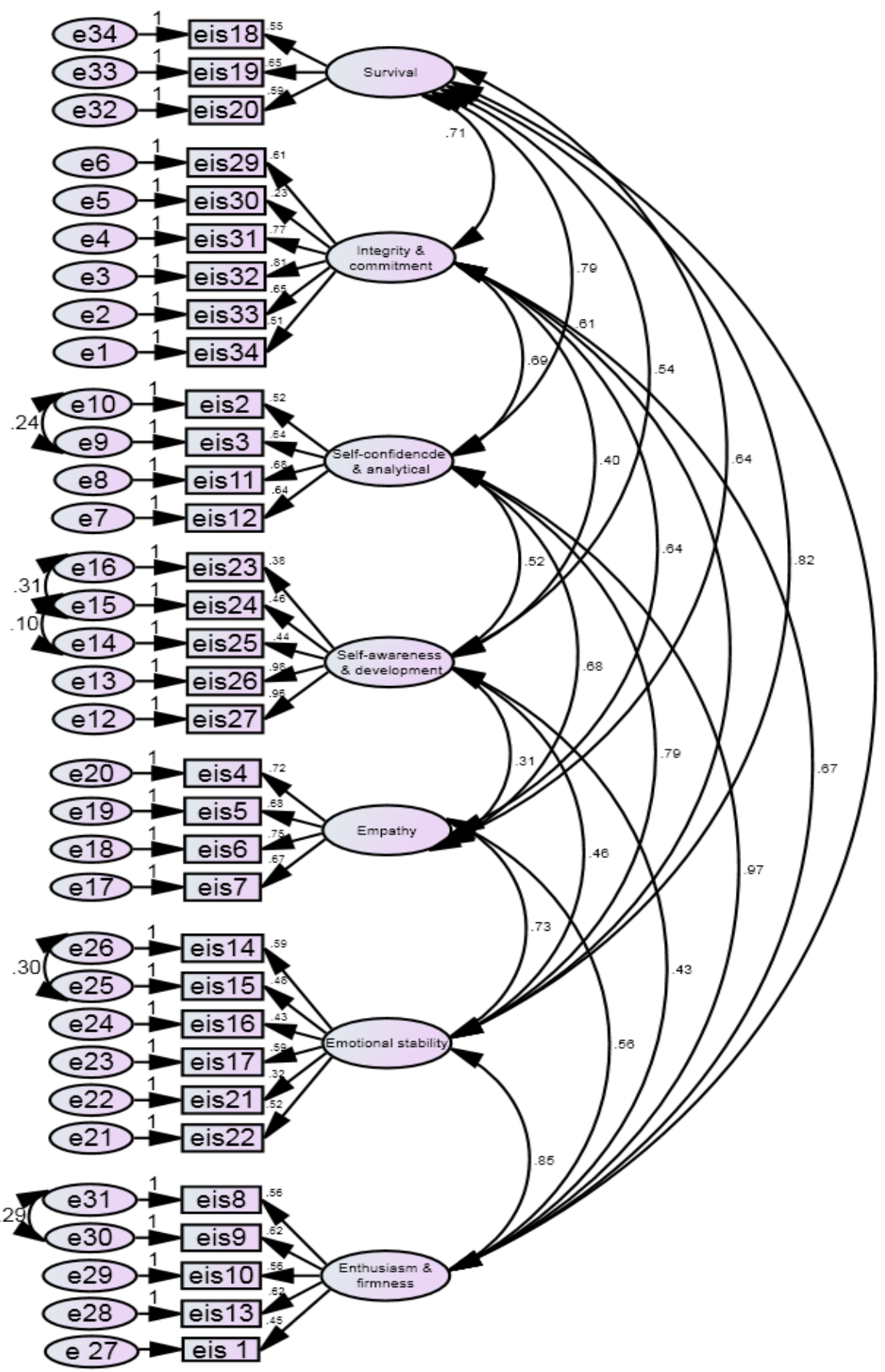

Figure 3. Factor structure of the seven-factor solution for the EIS (Standardized parameter).

(C) The International Journal of Indian Psychology, ISSN 2348-5396 (e)| ISSN: 2349-3429 (p) | 97 
Note. Items 2 and 3 were allowed to covary due to their similar content (self-understanding) and modification indices. This was also done for items 8 and 9 (ability), items 14 and 15 (feelings) and items 23 and 24 (positive attitudes) and items 23 and 25 (achievement). (Barke, Nyenhuis., \& Kroner-Herwig, 2012; Balkin, Harris, Freeman., \& Huntington, 2013; Lowe, Ang., \& Loke, 2011; Walker, 2010).

The above figure displays standardized parameters. As we see, factor loadings of the seven factors varied from .23 to .98. Particularly good at assessing, their latent variables were items which have the largest factor loadings. These are eis26 (.98) for the latent variable 'Selfawareness and Development', eis19 (.65) for Survival, eis32 (.81) for 'Integrity and Commitment', eis3 (.64) and eis12 (.64) for 'Self-confidence and Analytic', eis6 (.75) for Empathy, eis14 (.59) and eis17 (.59) for 'Emotional Stability', and eis9 (.62) and eis13 (.62) for 'Enthusiasm and Firmness'. The lowest factor loading was for item no. 30 (.23) under the latent variable 'Integrity and Commitment'. The correlations among latent variables varied from .31 to .97.The lowest correlation $(r=.32)$ was found between 'Self-awareness and Development' and 'Empathy'. The highest correlation ( $r=.97)$ was found between 'Self-confidence and Analytic' and 'Enthusiasm and Firmness'. This correlation indicates that these two latent variables are inseparable among the seven-factor model of EIS.

The standardized factor coefficients obtained in CFA are presented in comparison with those found in EFA in Table 4. The figures in this table indicate that the coefficients obtained in CFA are fairly consistent with those obtained in EFA.

\section{Table 4, Factor loadings from exploratory and confirmatory factor analysis on EIS (Seven- factor model)}

\begin{tabular}{|c|c|c|c|c|c|c|c|c|c|c|c|c|c|c|}
\hline \multirow{3}{*}{$\begin{array}{l}\text { Item } \\
\text { number }\end{array}$} & \multicolumn{14}{|c|}{ Factor loadings } \\
\hline & \multicolumn{2}{|c|}{$\begin{array}{l}\text { F1: Self- } \\
\text { confidence } \\
\text { \& analytic }\end{array}$} & \multicolumn{2}{|c|}{$\begin{array}{l}\text { F2: Self- } \\
\text { awareness \& } \\
\text { development }\end{array}$} & \multicolumn{2}{|c|}{$\begin{array}{l}\text { F3: } \\
\text { Empathy }\end{array}$} & \multicolumn{2}{|c|}{$\begin{array}{l}\text { F4: } \\
\text { Emotional } \\
\text { stability }\end{array}$} & \multicolumn{2}{|c|}{$\begin{array}{l}\text { F5: } \\
\text { Enthusias } \\
\text { m \& } \\
\text { firmness }\end{array}$} & \multicolumn{2}{|c|}{$\begin{array}{l}\text { F6: Integrity } \\
\text { \& } \\
\text { Commitment }\end{array}$} & \multicolumn{2}{|c|}{$\begin{array}{l}\text { F7: } \\
\text { Survival }\end{array}$} \\
\hline & EFA & CFA & EFA & CFA & EFA & CFA & EFA & CFA & EFA & CFA & EFA & CFA & EFA & CFA \\
\hline Item 02 & .60 & .52 & & & & & & & & & & & & \\
\hline Item 03 & .67 & .64 & & & & & & & & & & & & \\
\hline Item 11 & .58 & .68 & & & & & & & & & & & & \\
\hline Item 12 & .65 & .64 & & & & & & & & & & & & \\
\hline Item 23 & & & .44 & .38 & & & & & & & & & & \\
\hline Item 24 & & & .53 & .46 & & & & & & & & & & \\
\hline Item 25 & & & .59 & .44 & & & & & & & & & & \\
\hline Item 26 & & & .89 & .98 & & & & & & & & & & \\
\hline Item 27 & & & .87 & .96 & & & & & & & & & & \\
\hline Item 04 & $(.43)$ & & & & .61 & .72 & & & & & & & & \\
\hline Item 05 & & & & & .73 & .68 & & & & & & & & \\
\hline
\end{tabular}


Emotional Intelligence Scale: Assessing its Psychometric Characteristics in Bangladeshi Culture

\begin{tabular}{|c|c|c|c|c|c|c|c|c|c|c|c|c|c|c|}
\hline \multirow{3}{*}{$\begin{array}{l}\text { Item } \\
\text { number }\end{array}$} & \multicolumn{14}{|c|}{ Factor loadings } \\
\hline & \multicolumn{2}{|c|}{$\begin{array}{l}\text { F1: Self- } \\
\text { confidence } \\
\text { \& analytic }\end{array}$} & \multicolumn{2}{|c|}{$\begin{array}{l}\text { F2: Self- } \\
\text { awareness \& } \\
\text { development }\end{array}$} & \multicolumn{2}{|c|}{$\begin{array}{l}\text { F3: } \\
\text { Empathy }\end{array}$} & \multicolumn{2}{|c|}{$\begin{array}{l}\text { F4: } \\
\text { Emotional } \\
\text { stability }\end{array}$} & \multicolumn{2}{|c|}{$\begin{array}{l}\text { F5: } \\
\text { Enthusias } \\
\text { m \& } \\
\text { firmness }\end{array}$} & \multicolumn{2}{|c|}{$\begin{array}{l}\text { F6: Integrity } \\
\text { \& } \\
\text { Commitment }\end{array}$} & \multicolumn{2}{|c|}{$\begin{array}{l}\text { F7: } \\
\text { Survival }\end{array}$} \\
\hline & EFA & CFA & EFA & CFA & EFA & CFA & EFA & CFA & EFA & CFA & EFA & CFA & EFA & CFA \\
\hline Item 06 & & & & & .74 & .75 & & & & & & & & \\
\hline Item 07 & & & & & .71 & .67 & & & & & & & & \\
\hline Item 14 & & & & & & & .64 & .59 & & & & & & \\
\hline Item 15 & & & & & & & .60 & .48 & & & & & & \\
\hline Item 16 & & & & & & & .63 & .43 & & & & & & \\
\hline Item 17 & & & & & & & .53 & .59 & & & & & & \\
\hline Item 21 & & & & & & & .60 & .32 & & & & & & \\
\hline Item 22 & & & & & & & .49 & .52 & & & & & & \\
\hline Item 08 & & & & & & & & & .64 & .56 & & & & \\
\hline Item 09 & & & & & & & & & .73 & .62 & & & & \\
\hline Item 10 & & & & & & & & & .43 & .56 & & & & \\
\hline Item 13 & & & & & & & & & .48 & .62 & & & & \\
\hline Item 01 & & & & & & & & & .44 & .45 & & & $\begin{array}{l}(- \\
.42)\end{array}$ & \\
\hline Item 29 & $(.45)$ & & & & & & & & & & .41 & .61 & & \\
\hline Item 30 & & & & & & & & & & & .70 & .23 & & \\
\hline Item 31 & & & & & & & & & & & .48 & .77 & & \\
\hline Item 32 & $(.48)$ & & & & & & & & & & .42 & .81 & & \\
\hline Item 33 & & & & & & & & & & & .65 & .65 & & \\
\hline Item 34 & & & & & & & & & & & .58 & .51 & & \\
\hline Item 18 & & & & & & & & & & & & & .63 & .55 \\
\hline Item 19 & & & & & & & & & & & & & .52 & .65 \\
\hline Item 20 & & & & & & & & & & & & & .44 & .59 \\
\hline Eigenvalue & 3.22 & & 3.19 & & 2.96 & & 2.94 & & 2.45 & & 2.37 & & 1.83 & \\
\hline $\begin{array}{l}\text { Variance } \\
\text { explained } \\
(\%)\end{array}$ & 9.78 & & 9.66 & & 8.98 & & 8.92 & & 7.41 & & 7.20 & & 5.54 & \\
\hline
\end{tabular}

\section{Validity}

As reported by the judges the Bangla version EIS has good content validity (See the method section for details). The face validity of the Bangla version EIS was examined by getting comments about the readability, logicality, clarity, comprehensiveness, easily answerable, and 'style and formatting' of the scale items (Table 1). Thus, the measure has good face validity. Both the face and content validity ensured translation validity of the scale.

The convergent validity of the Bangla version EIS was examined by correlating with SES (School engagement scale) and FAS (Future aspiration scale). Results indicate that EIS has positive and significant correlation with above mentioned scales, such as between EIS and SES 
Emotional Intelligence Scale: Assessing its Psychometric Characteristics in Bangladeshi Culture

$(r=.30, p<.01)$, between EIS and FAS $(r=.26, p<.01)$. On the other hand, the discriminant validity was checked by correlating between EIS and CHS (Children hopelessness scale), between EIS and HS (Hostility scale). The EIS has negative and significant correlation with CHS $(r=-.34, p<.01)$, and HS $(r=-.16, p<.01)$ which indicates that the scale has good discriminant validity. Both convergent and discriminant validity refers to empirical validity of the scale.

The convergent validity of the Bangla version EIS was also examined by estimating inter-factor correlations and the factor-total correlations. The inter-factor correlations (Pearson's $r$ ) were all positively significant, with the coefficient ranging from .39 to .66 (Table 5). The seven factors also significantly correlated with the full EIS, with the coefficient of .70 to .79 .

Table 5 Correlation matrix for EIS and its factors

\begin{tabular}{|l|l|l|l|l|l|l|l|l|}
\hline EIS factors/EIS & $\begin{array}{l}\text { F1: } \\
\text { SCA }\end{array}$ & $\begin{array}{c}\text { F2: } \\
\text { SAD }\end{array}$ & $\begin{array}{l}\text { F3: } \\
\text { EM }\end{array}$ & $\begin{array}{l}\text { F4: } \\
\text { ES }\end{array}$ & $\begin{array}{l}\text { F5: } \\
\text { EF }\end{array}$ & $\begin{array}{l}\text { F6: } \\
\text { IC }\end{array}$ & $\begin{array}{l}\text { F7: } \\
\text { SU }\end{array}$ & EIS \\
\hline $\begin{array}{l}\text { F1: Self-confidence and } \\
\text { Analytic (SCA) }\end{array}$ & 1 & & & & & & & \\
\hline $\begin{array}{l}\text { F2: Self-awareness and } \\
\text { Development (SAD) }\end{array}$ & $.52^{* *}$ & 1 & & & & & & \\
\hline F3: Empathy (E) & $.52^{* *}$ & $.39^{* *}$ & 1 & & & & & \\
\hline F4: Emotional Stability (ES) & $.50^{* *}$ & $.49^{* *}$ & $.48^{* *}$ & 1 & & & & \\
\hline $\begin{array}{l}\text { F5: Enthusiasm and Firmness } \\
\text { (EF) }\end{array}$ & $.66^{* *}$ & $.46^{* *}$ & $.46^{* *}$ & $.43^{* *}$ & 1 & & & \\
\hline $\begin{array}{l}\text { F6: Integrity and Commitment } \\
\text { IC) }\end{array}$ & $.53^{* *}$ & $.51^{* *}$ & $.49^{* *}$ & $.45^{* *}$ & $.51^{* *}$ & 1 & & \\
\hline F7: Survival (S) & $.50^{* *}$ & $.51^{* *}$ & $.47^{* *}$ & $.55^{* *}$ & $.44^{* *}$ & $.52^{* *}$ & 1 & \\
\hline EIS & $.79^{* *}$ & $.76^{* *}$ & $.70^{* *}$ & $.75^{* *}$ & $.76^{* *}$ & $.77^{* *}$ & $.73^{* *}$ & 1 \\
\hline
\end{tabular}

Note. $N=1000 .{ }^{* *} P<.01$.

\section{Reliability}

The inter-item correlation matrix of the scale contained no negative values, indicating that the items were measuring the characteristics that the respective scale was supposed to measure. The reliability of the Bangla version of the scale was further examined by estimating internal consistency. The coefficient of the Cronbach's $\alpha$ was calculated. Cronbach's $\alpha$ (Unstandardized) for the Bangla version EIS was .93 for the $1^{\text {st }}$ sample, .92 for the $2^{\text {nd }}$ sample, and .92 for the combined sample. The coefficients for the 'Self-confidence and Analytic', 'Self-awareness and Development', Empathy, Emotional Stability, 'Enthusiasm and Firmness', 'Integrity and Commitment', and Survival were $.80, .83, .80, .72, .72$, .76, and .67 for the $1^{\text {st }}$ sample; $.73, .81$, $.80, .66, .71, .74$, and .62 for the $2^{\text {nd }}$ sample, and $.77, .82, .80, .69, .71, .75$, and .58 for the combined sample. 


\section{DISCUSSION}

The present study was designed to investigate the psychometric properties of a Bangla version of the EIS in the socio-cultural context of Bangladesh. Pilot study ensured the appropriateness of the measure as participants responded from $82 \%$ to $97 \%$ of different aspects of the measure. Item analysis contained no negative values and $98.93 \%$ inter-item correlations were significant. The item analysis indicates the test items are simple, congruent, and valid with the test objectives.

Analysis of the data in EFA identified a seven-factor model for the EIS comprising 33 items (only 1 item dropped; Table 2). Factor 1 (4 items) measures 'Self-confidence and Analytic', Factor 2 (5 items) measures 'Self-awareness and Development', Factor 3 (4 items) measures 'Empathy', Factor 4 (6 items) measures 'Emotional Stability', Factor 5 (5 items) measures 'Enthusiasm and Firmness', Factor 6 (6 items) measures 'Integrity and Commitment', and Factor 7 (3 items) measures 'Survival'. These factors together accounted for $56.60 \%$ of the total variance, their individual contributions ranging from 5.54\% to $9.78 \%$ (Table 2). Among ten components of original scale the name of four components ('Self-motivation', 'Managing Relation', 'Value Orientation', and 'Altruistic Behaviour') are removed in the adapted scale after factor analysis except their own items respectively. One component namely 'Survival' has included in the adapted scale.

Now, the adapted EIS is composed of seven components with 33 items of the original scale. This massive agreement regarding EIS between Indian and Bangladeshi culture reveals that the adapted seven-three factors emotional intelligence scale is common and stable across both the cultures. Most of the socio-cultural characteristics, cultural norms, habits, and socio-economic conditions are the same in both the countries. These factors are, probably, made similarities of EIS between the two countries. Despite the similarities item no. 28 (I am persistent in pursuing goals despite obstacles and setbacks) of 'Emotional Stability' component is removed in the adapted version. This discrepancy might be due to cultural variation between the India and Bangladesh. So, the finding is consistent with the original scale which comprises ten factors (Hyde et al., 2002).

Results of the CFA demonstrated good model fit to the data $\left[\chi^{2}(469)=1325.99\right.$, RMSEA $=.06$, $\mathrm{RMR}=.08, \mathrm{CFI}=.87, \mathrm{GFI}=.86]$, and also a factor solution which is consistent with the EFA factor solution. The factors of the Bangla version EIS shows moderate to good internal consistency (Cronbach's $\alpha=.58$ to .82), the second factor being most reliable as indicated by its highest coefficient (Cronbach's $\alpha=.82$ ). Experts (e.g., Cortina, 1930; Kline, 1999) reported that value below .70 can realistically be considered due to the diversity of the construct being measured in behavioral science. All the factors have significant correlations with the EIS ( $r=.70$ to .79; Table 5). In order to examine the convergent and discriminant validity, it was hypothesized that EIS should be positively correlated with FAS and SES in order for its 
Emotional Intelligence Scale: Assessing its Psychometric Characteristics in Bangladeshi Culture

convergent validity, and negatively correlated with CHS and HS for its discriminant validity. As hypothesized, EIS has significantly positive correlations with FAS and SES and significantly negative correlations with CHS, and HS. All this together indicate that the EIS has good convergent and discriminant validity.

Therefore, the adapted Bangla version EIS may be considered as a valid and reliable instrument for assessing emotional intelligence behavior of the adolescents in Bangladesh. Thus, the Bangla version EIS comprises 33 items Likert-type, with a minimum obtainable score of 33 and a maximum score of 165 . The adapted EIS scale can be useful to identify the nature of emotional intelligence behavior of adolescent students in Bangladesh. Research study using this tool can help us to design regarding how to minimize emotional intelligence, reduce negative and unexpected emotional intelligence behaviors of adolescents, examines reasons for such behavior and gives suggestions for dealing with it, and finally how to learn sound emotional intelligence behavior etc.

Despite advantages this study suffers from a number of limitations. The study confined mainly Dhaka city, not cover all over the Bangladesh which is obstacle for overall generalization. Though the sample size (1000) is sufficient for factor analysis, but contrary to, population (approximately 52,000) it is very much low. The second shortcoming is only eleventh grade adolescents were considered in the present study but other age range of adolescents were not considered. So, future studies should address the question of validating the EIS on other age range of adolescents. Despite these limitations, the present findings can serve as a base further research on the emotional intelligence behavior in Bangladeshi adolescents.

\section{Acknowledgments}

The author appreciates all those who participated in the study and helped to facilitate the research process.

\section{Conflict of Interests}

The author declared no conflict of interests.

\section{Funding source:}

Ministry of Science and Technology, People’s Republic of Bangladesh

\section{REFERENCES}

Abisamra, N. (2000). The relationship between emotional intelligent and academic achievement in eleventh graders. Research in Education, FED. 661.

Alegre, A. (2011). Parenting styles and children's emotional intelligence: What do we know? The Family Journal: Counselling and Therapy for Couples and Families, 19(1), 56-62. 
Emotional Intelligence Scale: Assessing its Psychometric Characteristics in Bangladeshi Culture

Aremu, A. O. (2004). Psychological and sociological determinant of academic achievement of Nigeria adolescents. An international Journal of Psychology in Africa, 12(2), 149-161.

Balkin, R. S., Harris, N. A., Freeman, S. J., \& Huntington, S. (2013).The forgiveness reconciliation inventory: An instrument to process through issue of forgiveness and conflict. Measurement and Evaluation in Counseling and Development, 47(1), 3-13.

Barke, A., Nyenhuis, N., \& Kroner-Herwig, B (2012). The German version of the Internate addiction test: A validation study. Cyber psychology, Behavior and Social Networking, 15(10), 534-542.

Barling, J., Slater, F., \& Kelloway, E. K. (2000). Transformational leadership and emotional intelligence: An exploratory study. Leadership and Organization Development Journal, 21(3), 157-161.

Bar-On, R. (2006). The Bar-On model of emotional-social intelligence (ESI). Psicothema, 18, 13-25.

Bhatia, G. (2012). A study of family relationship in relation to emotional intelligence of the students of secondary level. International Journal of Scientific and Research Publications, 2(12), 1-5.

Bolton, R. N., \& Bronkhorst, T. (1996). Questionnaire pretesting: Computer-assisting coding of concurrent protocols. In N. Schwarz \& S. Sudman (Eds.), In answering questions (3764). San Francisco: Jossey-Bass.

Braun, M. (2003). Errors in comparative survey research: An overview. In J. A. Harkness, E. J. R. Van de Vijver \& P. Mohler (Eds.), Cross-cultural survey methods (pp. 137-142). Hoboken, NJ: Wiley.

Center for Urban Affairs and Policy Research. (1995). Psychological and cognitive assessment. In L. L. Dahlberg, B. S. Toal, H. M. Swahn \& B. C. Behrens (Eds.), Measuring violencerelated attitudes, behaviors and influences among youths: A compendium of assessment tools (pp. 62-63). Atlanta, Georgia: Centers for Disease Control and Prevention.

Derogatis, L. R., Rickles, K., \& Rock, A. F. (1976). Psychological and cognitive assessment. In L. L. Dahlberg, B. S. Toal, H. M. Swahn \& B. C. Behrens (Eds.), Measuring violencerelated attitudes, behaviors and influences among youths: A compendium of assessment tools (pp. 64-65). Atlanta, Georgia: Centers for Disease Control and Prevention.

Eisenberg, N., \& Morris, A. S. (2002). Children's emotion-related regulation. In H. Reese \& R. Kail (Eds.), Advances in Child Development and Behavior (pp. 189-229). San Diego, CA: Academic Press.

Erkus, A. (1994). Dictionary of psychological terms. Ankara: Doruk Publishing House.

Goleman, D. (1995). Emotional Intelligence: Why it can matter more than IQ. New York, NY: Bantam books.

Goleman, D. (2001). Emotional intelligence. (Translator: Banu Seçkin Yüksel), İstanbul: Varlık Publication.

Goleman, D. (2006). Emotional intelligence. London: Bloomsbury Publishing.

Goldsmith, H. H., \& Davidson, R. J. (2004). Disambiguating the components of emotion 
regulation. Child Development, 75, 361-365.

Han, H., \& Johnson, S. D. (2012). Relationship between students' emotional intelligence, social bond, and interactions in online learning. Educational Technology \& Society, 15(1), 78-89.

Harkness, J. A. (2008). Comparative survey research: Goals and challenges. In E. D. de Leeuw, J. J. Hox \& D. A. Dillman (Eds.), International handbook of survey methodology (pp. 56-77). New York/London: Lawrence Erlbaum Associates.

Huffman, K. (2008). Psychology in Action (9 ${ }^{\text {th }}$ ed.). New York, NY: John Wiley \& Sons.

Hunt, S. D., Sparkman, R. D., \&Wilcox, J. B. (1982). The pretest in survey research: Issues and preliminary findings. Journal of Marketing Research, 19, 269-273.

Hyde, A., Pethe, S., \& Dhar, U. (2002). Manual for emotional intelligence scale. Lucknow, India: Vedanta Publications.

Kaiser, H. F. (1970). A second generation little jiffy. Psychometrika, 35(4), 401-415.

Karim, A. K. M., \& Nigar, N. (2014).The Internate addiction test: Assessing its psychometric properties in Bangladeshi culture. Asian Journal of Psychiatry, 10, 75-83.http://dx.doi.org /10.1016/j.ajp.2013.10.011

Kazdin, A. E., French, N. H., Unis, A. S., Esveldt-Dawson, K., \& Sherick, R. B. (1983). Psychological and cognitive assessment. In L. L. Dahlberg, B. S. Toal, H. M. Swahn \& B. C. Behrens (Eds.). Measuring violence-related attitudes, behaviors and influences among youths: A compendium of assessment tools (pp. 64-65). Atlanta, Georgia: Centers for Disease Control and Prevention.

Kazdin, A. E., Rodgers, A., \& Colbus, D. (1986). The hopelessness scale for children: Psychometric characteristics and concurrent validity. Journal of Consulting and Clinical Psychology, 54, 241-245.

Kline, P. (1999). The handbookof psychological testing ( $2^{\text {nd }}$ ed.). London: Routledge.

Lowe, P. A., Ang, R. P., \& Loke, S. W. (2011). Psychometric analyses of the test anxiety scale for elementary students (TAS-E) scores among Singapore primary school students. Journal of Psychopathology and Behavior Assessment, 33, 547-558.

Mayer, J. D., \& Salovey, P. (1997). What is emotional intelligence? In P. Salovey \& D. Sluyter (Eds.), Emotional development and emotional intelligence: Implications for educators (pp. 3-31). New York, NY: Basic Books.

Nixon, C., \& Watson, A. (1999) Adolescence: The mediating and moderating roles of self-efficacy beliefs. Merrill-Palmer Quarterly, 47(2), 165-187.

Rice, K. G., Cunningham, T. J., \& Young, M. B. (1997). Attachment to parents, social competence, and emotional well-being: A comparison of black and white late adolescents. Journal of Counseling Psychology, 44, 89-101.

Smith, G. T., \& McCarthy, D. M. (1995). Methodological considerations in the refinement of clinical assessment instruments. Psychological Assessment, 7, 300-308.

Spirito, A., Williams, C. A., Stark, L. J., \& Hart, K. J. (1988). The Hopelessness scale for children: Psychometric properties with normal and emotionally disturbed adolescents. Journal of Abnormal Child Psychology, 16, 445-458. 


\section{Emotional Intelligence Scale: Assessing its Psychometric Characteristics in Bangladeshi Culture}

Suess, G. J., Grossmann, K. E., \& Sroufe, L. A. (1992). Effects of infant attachment to mother on quality of adaptation in preschool: From dyadic to individual organization of self. International Journal of Behavioral Development, 15, 43-65.

Wagner, J. L., Smith, G., Ferguson, P. L., Horton, S., \& Wilson, E. (2009). A hopelessness model of depressive symptoms in youth with epilepsy. Journal of Pediatric Psychology, 34, 89-96.

Walden, T. A., \& Smith, M. C. (1997). Emotion regulation. Motivation and Emotion, 21, 7-25.

Walker, D. A. (2010). A confirmatory factor analysis of the attitudes toward research scale. Multiple Linear Regression Viewpoints, 36(1), 18-27.

Warhol, J. G. (1998). Facilitating and encouraging healthy emotional development. Pediatrics, 102(5), 1330-1331.

Williams, W. M., \& Sternberg, R. J. (1988). Group intelligence. Intelligence, 12, 351-377.

How to cite this article: Uzzaman A, Karim A (2017), Emotional Intelligence Scale: Assessing its Psychometric Characteristics in Bangladeshi Culture, International Journal of Indian Psychology, Volume 4, Issue 2, No. 86, ISSN:2348-5396 (e), ISSN:2349-3429 (p), DIP:18.01.032/20170402, ISBN:978-1-365-68609-2 